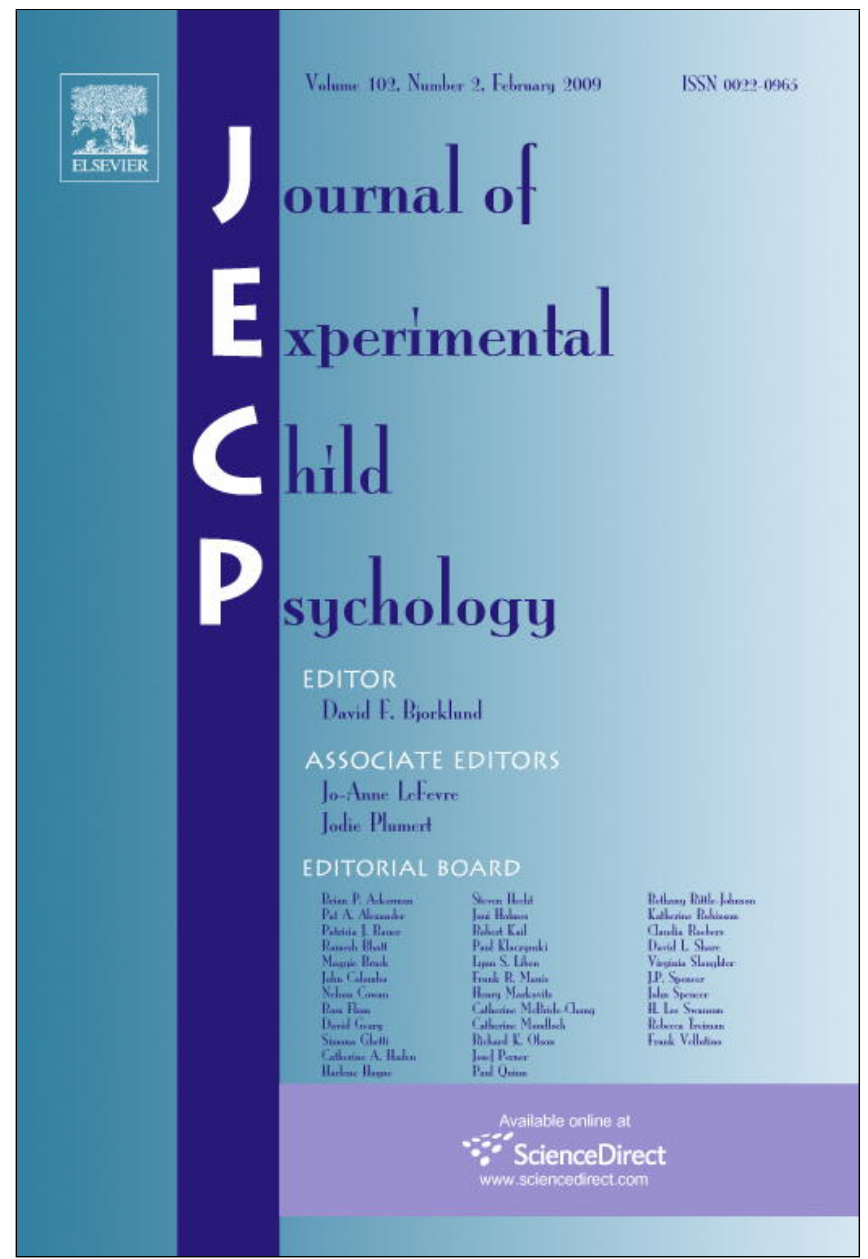

This article appeared in a journal published by Elsevier. The attached copy is furnished to the author for internal non-commercial research and education use, including for instruction at the authors institution and sharing with colleagues.

Other uses, including reproduction and distribution, or selling or licensing copies, or posting to personal, institutional or third party websites are prohibited.

In most cases authors are permitted to post their version of the article (e.g. in Word or Tex form) to their personal website or institutional repository. Authors requiring further information regarding Elsevier's archiving and manuscript policies are encouraged to visit:

http://www.elsevier.com/copyright 
Reply

\title{
Nature versus nurture: The simple contrast
}

\author{
Jules Davidoff ${ }^{\mathrm{a}, *}$, Julie Goldstein ${ }^{\mathrm{a}}$, Debi Roberson ${ }^{\mathrm{b}, *}$ \\ a Department of Psychology, Goldsmiths, University of London, London SE14 6NW, UK \\ ${ }^{\mathrm{b}}$ Department of Psychology, University of Essex, Colchester CO4 3SQ UK
}

\section{A R T I C L E I N F O}

\section{Article history:}

Received 11 September 2008

Available online 7 November 2008

\section{Keywords:}

Cross-cultural perception

Categorical perception

Whorf

Color terms

Perceptual development

\section{A B S T R A C T}

We respond to the commentary of Franklin, Wright, and Davies (Journal of Experimental Child Psychology, 102, 239-245 [2009]) by returning to the simple contrast between nature and nurture. We find no evidence from the toddler data that makes us revise our ideas that color categories are learned and never innate.

(c) 2008 Elsevier Inc. All rights reserved.

In their commentary, Franklin, Wright, and Davies (2009) raise a number of questions concerning both the theoretical framework of our argument and the validity of our results (Goldstein, Davidoff, \& Roberson, 2009). We first respond to their commentary on the theoretical framing and then to the results and methodological issues that arise from them.

At the end of their commentary, Franklin, Wright, and Davies (2009) welcome that the debate on color categories has moved away from a simple contrast between nature and nurture even though this is exactly the framing of the argument presented in the introduction to their 2005 article (Franklin, Pilling, \& Davies, 2005). In this response, we argue that it is too soon to abandon debate about the simple contrast. Of course, we are pleased that it is now generally acknowledged that language plays a substantial role in the establishment of even basic level color categorical perception (e.g., Gilbert, Regier, Kay, \& Ivry, 2006). However, their commentary still presents a "neonativist" position in that it holds the primacy of inborn color categories.

Franklin et al. (2009) argue, based on the infant data in Franklin et al. (2008), that the right hemisphere of the brain is imbued with innate color categorical properties but the left hemisphere learns color categories and, most important, that the left hemisphere then holds the default categorical system. In adults, when the dominant left hemisphere system is suppressed by a concurrent task that prevents access to verbal codes, or when it cannot be reached in split-brain patients, no trace of

\footnotetext{
* Corresponding authors. Fax: +44 2070785145 (J. Davidoff), +44 120687380 (D. Roberson).

E-mail addresses: j.davidoff@gold.ac.uk (J. Davidoff), robedd@essex.ac.uk (D. Roberson).
} 
categorical organization in the right hemisphere remains (Gilbert et al., 2006; Roberson \& Davidoff, 2000; Winawer et al., 2007). However, although this much is agreed by researchers on both sides of the theoretical debate, it is still difficult to understand why only the right hemisphere should show the innate color categories found in Franklin et al. (2008). How could these categories come about when the visual input from the retina is the same to both hemispheres? There is no physiological evidence that there are cortical cells with these properties anywhere close to visual cortex, nor is there any behavioral evidence that they persist once linguistic categories are learned.

The original infant work (Bornstein, Kessen, \& Weiskopf, 1976) was flawed because it did not use psychologically equal interval steps between colors. When that group of researchers turned to monkeys (Sandell, Gross, \& Bornstein, 1979), they correctly changed to Munsell stimuli but, still having in mind wavelength differences, got the separations wrong. They made the cross-category comparisons substantially easier than the within-category comparisons (this can be seen by inspection of their article and was summarized in Goldstein, 2008). Later work with monkeys-which have the same retinal cone system as humans-could find no evidence for color categories (Fagot, Goldstein, Davidoff, \& Pickering, 2006). The Surrey group's initial infant research (Franklin \& Davies, 2004) does not suffer from any of the early faults with infant data and so must remain a substantial river for the nurture camp to cross. Our own attempt to replicate that work produced no evidence for color categories, but our 4-month-old participants found the task uninteresting and many became restless and untestable (Lupyan, 2006; Roberson \& Hanley, in press).

There are better new techniques used with infants, such as visual search, but these too have their problems. In testing infants, Franklin and colleagues (2008) used only three widely separated colors (one green target, one blue target, and a background color that was just on the green side of the boundary between green and blue) because those used for adults were too difficult for infants to discriminate. Thus, no direct comparison with adults can be made because the adults in the study saw a different set of colors. Furthermore, given the difficulties of carrying out eye-tracking studies with infants, the data came from only 13 infants. Nor have any infants to date been tested for the presence of other category boundaries (e.g., the category boundary between the Russian categories sinii and goloboy) that are not proposed to be part of any universal innate set. Therefore, it is premature to conclude that all prelinguistic infants show the same pattern of categorization as (English-speaking) adults across the full range of visible colors. Those authors' conclusion also stands at odds with the findings of Xu and Carey (2000), where 6-month-olds were found to be insensitive to much larger changes in the color of stimuli. Nevertheless, the infant data present a most interesting challenge to researchers in the field. Given the significance of the theoretical consequences of innate color categories, it is hoped that more infant laboratories will pursue investigations of these issues.

In an attempt to reconcile the existence of universal innate categories in preverbal infants with culturally and linguistically diverse sets of categories in older children and adults, Franklin and colleagues' (2009) commentary proposes two ways-apart from the understanding of color terms-in which a child's experience might contribute to the production of color categories. However, neither explanation can provide an adequate account of the currently available data. The first explanation is that different color categories might arise through different visual diets, but these natural illumination variations are highly unlikely to be relevant. The primary rainforest environment of the Berinmo (Roberson, Davies, \& Davidoff, 2000) is markedly different from the desert savannah environment of the Himba (Roberson, Davidoff, Davies, \& Shapiro, 2004), yet their categorizations are remarkably similar, as noted by Regier and Kay (2004). If color environment was important for the development of color categories, there would be more than the small boundary differences observed between these two populations, however important those small differences are for perceptual and memory judgments (Roberson, Davidoff, Davies, \& Shapiro, 2005). U.K. speakers of English and Welsh also share a similar visual environment, yet Welsh has no separate terms for blue and green.

Of course, the effect of visual environment might be indirect. Because most of the traditional cultures that have few color terms are located close to the equator, categorical differences might arise after damage to the retina caused by sunlight exposure, as argued by Lindsay and Brown (2002). However there is now evidence to the contrary (Hardy, Delahunt, Okajima, \& Werner, 2005; Regier \& Kay, 2004), and in any case, as noted by Laeng, Mathisen, and Johnsen (2007), "Observed differences in color vision were subtle, and they occurred within the normal range of human performance." 
The second possibility is that infants are able to make use of the statistical regularities of their environment (Younger, 1990). Younger's data came from 10-month-olds, although Quinn and colleagues have shown similar effects for younger children (e.g., Quinn \& Eimas, 1996). Interestingly, what might at first have been thought to be an innate appreciation of animal categories was found to be due to the use of statistical regularities in the differences between cat and dog pictures (French, Mareschal, Mermillod, \& Quinn, 2004). Clearly, the cognitive abilities of the 4-month-old human are more sophisticated than had been thought previously. However, this could not be the case for color categories that lack this kind of separable statistical regularity. Color forms a continuous perceptual domain that can be divided in a remarkably variable number of ways (Kay, Berlin, Maffi, \& Merrifield, 1997; MacLaury, 1987). Moreover, perceived color varies with changes in illumination to such an extent that the only available "statistical regularity" is generally the verbal label that is applied to a particular range of colors. Although a 1-year-old could make use of the regular association of a color word to a color sensation, it seems unlikely that a 4-month-old could do so.

For toddlers, who are the subject of the current article, one could point to many examples (e.g., Choi \& Bowerman, 1991; O'Hanlon and Roberson, 2006) where children are sensitive to the labeling regularities of their native language before they are able to accurately use the correct labels themselves. Thus, one could argue that all toddlers might have knowledge of color terms from such associations. Also, given that in both our data and the reanalysis by Franklin and colleagues (2009) the number of children who do not know color terms, even at 2 years of age, is very small, these factors could downplay the value of toddler research to answer the nature-nurture issue for color categories.

Turning to the data themselves, despite wishing to downplay the value of the toddler research, Franklin and colleagues (2009) still wish to show that eight of the children in their study showed categorical perception despite being unable to name focal colors. For clarity, the commentators should have made clear that these eight children whose data were reanalyzed were English. They should also, as we argued in our article (Goldstein, Davidoff, \& Roberson, 2009), have given the breakdown by boundary (e.g., four children who were tested on the blue-green boundary failed to name or comprehend both green and blue), and they should have given the within- and cross-category success rates separately for each boundary. We note that the very large size of the associated standard deviations may indicate that some children were at chance on both tasks. In our view, the data from children at chance on both tasks should have been removed from the sample because it is unclear whether those children understood the task. Our analyses excluded data from children whose performance was at chance. Inclusion of those data in our sample would remove any hint of a cross-boundary advantage for either the blue-green or blue-purple sets of stimuli and would make our contrasting result much more striking.

More important toddler data come from the Himba, where it is easier to claim that toddlers who do not know color terms should not show evidence for Western color categories. However, even for them, one might argue that they could have implicit understanding of their own terms and that these could suppress any innate mechanisms presumed to exist in the right hemisphere. If so, Himba toddlers would not show color categorical perception for Western categories. That is what we found for blue versus green, but new data supplied from an unpublished thesis (Wright, 2006) suggest that some Himba children do perceive blue and green categorically. However, these new data are not convincing. Wright (2006) reported results for a comparison of only two pairs of stimuli, and the only result to fall outside the 95\% confidence interval for either pair was that of English children for the cross-category pairs. Clearly, the Himba children tested by Wright found the task to be too difficult, and we regard this new evidence as less than weak support for innate categorization.

The unpublished data of Wright (2006) give no details as to where the data were collected. One possible explanation for the difference between our findings and those of Wright might relate to a circumstance highlighted by Franklin, Pilling, and Davies (2005). They reported excluding the blue-green boundary from testing because they had found that a number of Himba people used the borrowed term grine (green). In our recent visits to the area, we have also noted that the use of this term has become increasingly common, especially in villages where mobile schools operate. The toddlers in some areas, although not eligible to attend school themselves, might have heard adults or older children using the term if they were in a village with a mobile school. Indeed, we have found that to be a problem in our own data collection in some villages where only very young children appeared to be 


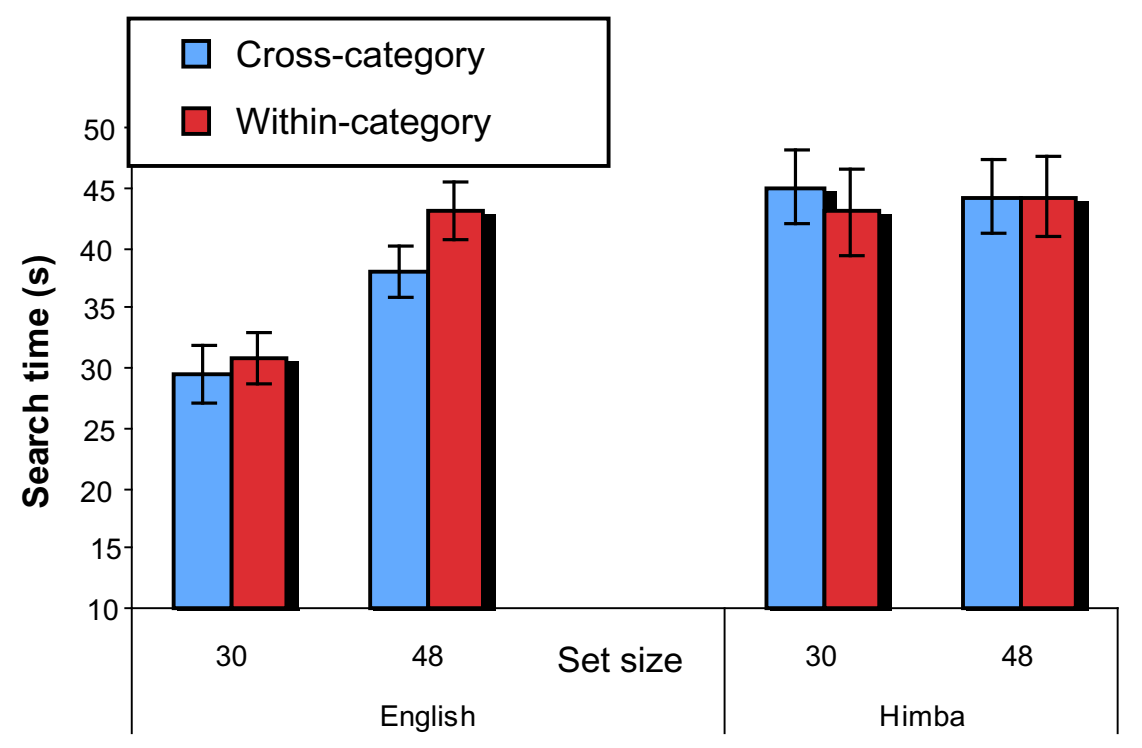

Fig. 1. Search time by English and Himba children for targets in small (30) or large (48) sets of distractors reported by Daoutis et al. (2006).

uncontaminated by borrowed color terms. Therefore, we conducted a second field trip to more remote locations where it was possible to find older toddlers who had no knowledge of borrowed color terms.

Our results do, however, concord well with other research on Himba children by those authors using a visual search task (Daoutis, Franklin, Riddett, Clifford, \& Davies, 2006). In those experiments, they found a significant category effect for English children that increased with set size (see Fig. 1), but they found no such effect for Himba children. They concluded, "Children can be aided by the category status of stimuli when performing visual search: when the target and distractors belong in different colour categories, search is more efficient. Moreover, this categorical advantage disappears if the target and distractors are not separated by a linguistic boundary" (p. 397). These results directly contradict the findings of Wright (2006). We note that here, as in Wright's data and Franklin et al., 2005 data, the performance of English children is faster and more accurate than that of Himba children of the same age. However, because this was a visual search task, the difference cannot be due to Himba children's lack of training on memory tasks. It seems more likely that performance differences in all cases are due to the increased task difficulty that accompanies the lack of separate verbal codes for targets and distracters.

In conclusion, we agree with Franklin and colleagues (2009) that toddlers may be influenced by the linguistic categorizations of their native community before they accurately apply the appropriate category labels; this has already been demonstrated in other modalities. Thus, we also agree that these populations are not the best ones to test for the existence of an innate set of color categories. We disagree, however, that the currently available evidence is sufficient to allow us to conclude that all humans have an innate set of color categories resembling that of (English-speaking) adults, especially given that even English-speaking adults, under verbal suppression, show no evidence of retaining such a set. We believe that debate on these issues should not be abandoned. Rather, we welcome a broadening of the debate and note that new techniques, such as functional magnetic resonance imaging (fMRI), are making a valuable contribution to issues such as the early involvement of language processing in perceptual decisions about color (Tan et al., 2008). In the meantime, our data in the target article (Goldstein et al., 2009) place important constraints on the previous conclusions about the presence of robust color categories before color terms are learned.

\section{References}

Bornstein, M. H., Kessen, W., \& Weiskopf, S. (1976). Color vision and hue categorization in young infants. Journal of Experimental Psychology: Human Perception and Performance, 1, 115-129.

Choi, S., \& Bowerman, M. (1991). Learning lo express motion events in English and Korean: The influence of language-specific lexicalization patterns. Cognition, 42, 83-121. 
Daoutis, C., Franklin, A., Riddett, A., Clifford, A., \& Davies, I. R. L. (2006). Categorical effects in children's colour search: A crosslinguistic comparison. British Journal of Developmental Psychology, 24, 373-400.

Daoutis, C. A., Pilling, M., \& Davies, I. R. L. (2006). Categorical effects in visual search for colour. Visual Cognition, 14, $217-240$.

Fagot, J., Goldstein, J., Davidoff, J., \& Pickering, A. (2006). Psychonomic Bulletin and Review, 13, 275-280.

Franklin, A., \& Davies, I. R. L. (2004). New evidence for infant colour categories. British Journal of Developmental Psychology, 22, 349-377.

Franklin, A., Drivonikou, G. V., Bevis, L., Davies, I. R. L., Kay, P., \& Regier, T. (2008). Categorical perception of color is lateralized to the right hemisphere in infants, but to the left hemisphere in adults. Proceedings of the National Academy of Sciences of the United States of America, 105, 3221-3225.

Franklin, A., Pilling, M., \& Davies, I. R. L. (2005). The nature of infant color categorization: Evidence from eye-movements on a target detection task. Journal of Experimental Child Psychology, 91, 227-248.

Franklin, A., Wright, O., \& Davies, I. R. L. (2009). What can we learn from toddlers about categorical perception of color? Comments on Goldstein, Davidoff, and Roberson. Journal of Experimental Child Psychology, 102, 239-245.

French, R. M., Mareschal, D., Mermillod, M., \& Quinn, P. C. (2004). The role of bottom-up processing in perceptual categorization by 3- to 4-month-old infants: Simulations and data. Journal of Experimental Psychology: General, 133, 382-397.

Gilbert, A. L., Regier, T., Kay, P., \& Ivry, R. B. (2006). Whorf hypothesis is supported in the right visual field but not the left. Proceedings of the National Academy of Sciences, 103, 489-494.

Goldstein, J. N. (2008). Language and culture in perception: A three-pronged investigation of phylogenetic, ontogenetic, and crosscultural evidence. Unpublished PhD thesis, Goldsmiths, University of London.

Goldstein, J., Davidoff, J., \& Roberson, D. (2009). Knowing color terms enhances recognition: Further evidence from English and Himba. Journal of Experimental Child Psychology, 102, 219-238.

Hardy, J. L., Delahunt, P. B., Okajima, K., \& Werner, J. S. (2005). Senescence of spatial chromatic contrast sensitivity: Detection under conditions controlling for optical factors. Journal of the Optical Society of America A, 22, 49-59.

Kay, P., Berlin, B., Maffi, L., \& Merrifield, W. R. (1997). Color naming across languages. In C. L. Hardin \& L. Maffi (Eds.), Color categories in thought and language. Cambridge, UK: Cambridge University Press.

Laeng, B., Mathisen, R., \& Johnsen, J. A. (2007). Why do blue-eyed men prefer women with the same eye color? Behavioral Ecology and Sociobiology, 61, 371-384.

Lindsay, D. T., \& Brown, A. M. (2002). Color naming and the phototoxic effects of sunlight on the eye. Psychological Science, 13, 506-512.

Lupyan, G. (2006). Labels facilitate learning of novel categories. In A. Cangelosi, A. D. M. Smith, \& K. Smith (Eds.), The Sixth International Conference on the Evolution of Language (pp. 190-197). Singapore: World Scientific.

MacLaury, R. E. (1987). Color-category evolution and Shuswap yellow-with-green. American Anthropologist, 89, 107-124.

O'Hanlon, C., \& Roberson, D. (2006). Learning in context: Linguistic and attentional constraints on children's color term learning. Journal of Experimental Child Psychology, 94, 275-300.

Quinn, P. C., \& Eimas, P. D. (1996). Perceptual cues that permit categorical differentiation of animal species in infants. Journal of Experimental Child Psychology, 63, 189-211.

Regier, T., \& Kay, C. (2004). Color naming and sunlight: A response to Lindsay and Brown (2002). Psychological Science, 15, 289-290.

Roberson, D., \& Davidoff, J. (2000). The categorical perception of colors and facial expressions: The effect of verbal interference. Memory and Cognition, 28, 977-986.

Roberson, D., Davidoff, J., Davies, I., \& Shapiro, L. R. (2004). The development of color categories in two languages: A longitudinal study. Journal of Experimental Psychology: General, 133, 554-571.

Roberson, D., Davidoff, J., Davies, I., \& Shapiro, L. R. (2005). Color categories: Evidence for the cultural relativity hypothesis. Cognitive Psychology, 50, 378-441.

Roberson, D., Davies, I., \& Davidoff, J. (2000). Color categories are not universal: Replications and new evidence from a Stone-Age culture. Journal of Experimental Psychology, 129, 369-398.

Roberson, D., \& Hanley, J. R. (in press). Relatively speaking: An account of the relationship between language and thought in the color domain. In B. Malt \& P. Wolff (Eds.), Words and the world: How words capture human experience. Oxford, UK: Oxford University Press.

Sandell, J. H., Gross, C. G., \& Bornstein, M. H. (1979). Color categories in Macaques. Journal of Comparative and Physiological Psychology, 93, 626-635.

Tan, L. H., Chan, A. H. D., Kay, P., Khong, P. L., Yip, L. K. C., \& Luke, K. K. (2008). Language affects patterns of brain activation associated with perceptual decision. Proceedings of the National Academy of Sciences of the United States of America, 105, 4004-4009.

Winawer, J., Witthoft, N., Frank, M. C., Wu, L., Wade, A. R., \& Boroditsky, L. (2007). Russian blues reveal effects of language on color discrimination. Proceedings of the National Academy of Sciences of the United States of America, 104, 7780-7785.

Wright, O. (2006). The origin and nature of perceptual colour categories. Unpublished PhD thesis, University of Surrey.

Xu, F., \& Carey, S. (2000). The emergence of kind concepts: A rejoinder to Needham and Ballargeon (2000). Cognition, 74, $285-301$.

Younger, B. (1990). Infants' detection of correlations among feature categories. Child Development, 61, 614-620. 